\title{
aniki
}

Revista Portuguesa da Imagem em Movimento

Portuguese Journal of the Moving Image

\section{Uma narrativa possível sobre os jogos criados em Portugal nos últimos anos. Reflexão a partir do livro Videojogos em Portugal: História, Tecnologia e Arte, de Nelson Zagalo (2013)} Patrícia Gouveia ${ }^{1}$

Nelson Zagalo. 2013. Videojogos em Portugal: História, Tecnologia e Arte. FCA Editora: Lisboa. 248pp. ISBN 978-972-722-765-5.

A história que Nelson Zagalo, professor auxiliar na Universidade do Minho e editor do blogue Virtual Illusion, nos relata no seu livro desenrola-se a partir de 1970 até $2012^{2}$, remetendo-nos para um catálogo de produções portuguesas organizadas cronologicamente e por tecnologias. O texto está dividido em nove partes e começa com uma introdução sobre o nascimento dos videojogos seguida dos desenvolvimentos formais organizados por períodos históricos. Neste contexto, podemos conhecer os pioneiros nacionais, entre 1970 e 1990, as tecnologias dos anos noventa, do MS-DOS ao CD-ROM, a criação da comunidade nacional, a partir de 1998, e seguir caminho através das tecnologias móveis, dos mundos on-line, das consolas, entre 2002 e 2008 , e, finalmente conhecer as novas formas de distribuição, desde 2009, e ler as conclusões do autor.

Este livro é um primeiro exercício de classificação e arrumação das produções nacionais e, nesse sentido, é de louvar todo o esforço dispendido na recolha de material, na pesquisa das fontes e na organização de um conjunto de trabalhos em secções. Faz-se um enquadramento histórico, anunciam-se os primeiros jogos, apresentam-se plataformas tecnológicas e a comunidade nacional, explicitam-se mundos criados em dispositivos móveis e on-line, consolas e novas tipologias de distribuição. Finalmente, sugerem-se algumas conclusões possíveis. Na sua generalidade esta é uma narrativa possível sobre os jogos criados em Portugal nos últimos anos.

Sobre a metodologia utilizada tenho algumas reservas pois, numa altura em que o campo de estudo há muito largou a especificidade de uma terminologia ancorada no termo "vídeo", a utilização deste parece-me problemática no contexto de um território mais vasto que não o de língua portuguesa. Desde o início da década passada que os estudos sobre jogos, que despoletaram em força nos países

\footnotetext{
${ }^{1}$ Universidade Nova de Lisboa, Faculdade de Ciências Sociais e Humanas, Departamento de Ciências da Comunicação, 1069-061 Lisboa, Portugal.

${ }^{2}$ Sendo que o primeiro jogo considerado pelo autor data de 1982 faz-se um enquadramento da área mais genérico no início do livro daí o aparecimento do ano de 1970.
} 
nórdicos por volta de 2001 com a publicação de uma revista académica (http://www.gamestudies.org), alertaram para a ineficiência de visões formatadas por cronologias históricas que pretendiam arrumar os jogos digitais em prateleiras estanques (listas e mapas). Outra crítica vigente, na época, era a de que a maioria dos livros sobre experiências lúdicas existentes, muitos deles produzidos por jornalistas na década precedente, anos 90, na Europa e nos Estados Unidos da América, se limitavam à organização em tipologias de género. Este livro apresenta ambos os estigmas e, por isso mesmo, contribui pouco para fomentar uma leitura mais abrangente do campo, o que restringe o seu objectivo final. Sofre, parece-nos, de um fascínio tecnológico que coloca os gadgets e os artifícios provenientes de uma indústria pouco consistente em primeiro plano. Apaga-se, assim, estrategicamente, qualquer fugaz tentativa de inovação e desenvolvimento que não surja nos parâmetros mais óbvios. Uma estética geek misturada com a "casa dos segredos" não é o único caminho. Uma perspectiva crítica mais apurada seria interessante uma vez que a pesquisa e a recolha de material, pelo menos na área que o autor domina, são vastas. Assim, o texto, vai-se transformando em propaganda porque ao evidenciar um dos lados da moeda (uma frágil indústria) apaga totalmente o outro (produtos criativos menos comerciais).

Este factor seria de somenos importância não fosse todo o livro estar enformado por noções muito estreitas daquilo que hoje, numa época de híbridos, convergência e estética transmedia, se podem considerar jogos. Ora, logo na página XIV o autor afirma: "Deste modo, trabalhámos todos os jogos criados em Portugal, comercializados ou não, desde que tenham tido algum tipo de apresentação pública em data verificável. A razão porque consideramos a distribuição não comercial prende-se com o facto de um jogo que sai hoje na App Store não ser diferente de um jogo feito para o ZX Spectrum e que nunca saiu do 'bairro'”. Se o fito deste catálogo é fazer uma recensão de todos os jogos criados em Portugal com algum tipo de apresentação pública então há alguns jogos criados por autores independentes, apresentados em galerias de arte, bibliotecas e museus, que não figuram sequer neste documento. Porquê? Que argumento é que sustenta que toda a produção artística independente seja "apagada" da história compilada e narrada por Nelson Zagalo? Refiro-me a jogos e CD-ROMs apresentados, por exemplo, no contexto do concurso Jovens Criadores desde 1998. O first person shooter, a partir de um motor do jogo Quake, criado e produzido pela Galeria ZBD de Lisboa, que pedia ao jogador que disparasse sobre políticos da "cena" nacional, nomeadamente o então ministro da cultura Manuel Maria Carrilho. Como esquecer a área multimédia dos Jovens Criadores, por exemplo, e apenas eleger as conferências na área dos Videojogos, muito mais recentes, e cuja organização está nas mãos do próprio autor do livro? Artefactos jogáveis, game arte, o que se lhes quiser chamar, com apresentações nacionais em museus e galerias e, no 
campo internacional, na Arco em Madrid, infelizmente não encaixam nesta história.

Estética do desaparecimento artístico independente em prol da propaganda a uma indústria que dá poucas mostras de vitalidade embora o autor considere, na página 178, que "Portugal teve muita dificuldade em chegar às consolas, mas quando chegou, fê-lo "em grande". Que tipo de grandeza mostra menos de uma dezena de títulos publicados, um dos quais não finalizado (cf. o exemplo de Ugo Volt com financiamento público e capital de risco) e onde foram gastas quantias consideráveis? É nestas afirmações que um certo discurso de propaganda se torna evidente que, embora seja desmontado logo no prefácio de António Saraiva pela saga megalomaníaca em Portalegre de 2006, persiste em não nos largar.

Considera António Saraiva: "No arranque decisivo daquilo que é este simulacro de indústria hoje - Portalegre em 2006 - o megalómano de serviço anunciou que Portugal seria responsável por 30\% do mercado global de videojogos em 2012. Este delírio de somenos importância, se silenciado, encontrou eco em certa imprensa nacional afligida de morte cerebral e fica, para nosso opróbrio colectivo, registado como o grotesco histórico que marca o nascimento das empresas modernas e mais viradas para o mercado. E contamina, de certo modo, a crítica ou a ausência dela. Em completa dissonância cognitiva, obras sem nenhuma relevância têm honras de telejornais e empresas de pouco futuro protagonizam páginas inteiras de jornais e revistas" (XII).

Ora, considera-se que este "catálogo" de jogos editado por Nelson Zagalo compromete qualquer visão crítica mais positiva uma vez que peca precisamente pelo mesmo estigma acima referido por António Saraiva. Sugere-se que uma emulação de um jogo do galo numa calculadora, trinta anos depois de A. S. Douglas ter feito algo semelhante na América (cf. Zagalo, 21-26), mais duas simulações matemáticas do tipo shooters, LASER e BALA, ambos de 1982, são a porta de entrada para a nossa história colectiva na área dos jogos digitais. Uma experiência de liceu, sem grande criatividade, criada por José Oliveira, que tinha 17 anos em 1982 - não esquecer que as primeiras interacções humano-máquina foram criadas a partir de meados do século passado - é colocada a par de outras obras que resultaram na efectiva criação de jogos que não emulações ou experiências tecnológicas. Considera-se que há qualquer coisa aqui que começa a não bater certo. Meras emulações do que se faz fora de fronteiras contrastam com esforços evidentes para produzir produtos inovadores, criativos e diferenciados. O mero "exercício" ombreia, na história narrada por Zagalo, com obras de interesse nacional.

O espaço dedicado no livro à explicação das inovações tecnológicas, embora não seja matéria nova e a informação prolifere em livros e sítios da especialidade em várias línguas, enquadra o territó- 
rio a explorar havendo, de salientar, uma preocupação pedagógica bem estruturada que se explicita pela escrita escorreita, simples e didáctica. O livro apresenta-se como uma possível viagem à história da multimédia, em geral, e aos jogos digitais, em particular. São, no entanto, as opções de selecção dos títulos que nos interpelam. No caso dos CD-ROMs do grupo Fórum, por exemplo, este aspecto é notório. Vê-se desaparecer a trilogia do azul da EXPO'98 (grande prémio multimédia XXI), uma parceria entre o grupo de criação e produção multimédia antes citado e a Parque Expo, com consultoria da Montparnasse Multimédia, uma prestigiada empresa francesa de produtos multimédia, mas aparecem outros títulos do mesmo grupo de pouca relevância nacional. No entanto, nesses CDs foram criados três simuladores de sensações, três jogos, em paralelo com a apresentação dos conteúdos enciclopédicos.

Onde está o Emotional Object de 2008/09, uma colaboração entre Adriana Sá (PT), John Klima (USA), Sofia Oliveira (PT) e Jared Hawkey? O jogo apresenta-se on-line como: "an interactive installation, Emotional Object is a multi-user game that invites to act upon a mechano-sculpture and a musical composition through a digital interface. The player proceeds while speculating about which emotion will result from a determined action, and about the effect of the individual over the collective." Este projecto, financiado pelo Instituto das Artes, foi apresentado não só na galeria ZDB em Lisboa como também no Centre pour L'Image Contemporaine na Suíça. As instalações e os playable media não entram no conceito de jogo de Nelson Zagalo? John Klima, para além de reconhecido artista digital, foi programador na Biodroid, empresa que financia parte deste livro e que é amplamente referenciada no mesmo. http://www.cada1.net/?p=70

Quantos mais títulos terão desaparecido por opção do autor? Os Serious Games, hoje um dos maiores "filões" de financiamento da União Europeia e da América, não são sequer referenciados neste livro e existem experiências nacionais nesta área. Estes jogos estão mesmo na génese da história do meio com o aparecimento das primeiras simulações em osciloscópio, com a criação da Arpanet (o projecto que deu azo à Internet) e, mais tarde, com os avultados orçamentos de investigação na área de entretenimento a serem financiados pelo exército americano. Alguns países na Europa, na China e no Médio Oriente seguiram esta estratégia de financiamento, o que sempre levantou inúmeras suspeições por parte da sociedade civil em relação aos jogos digitais. O argumento só pode ser que não cabem na classificação de jogos presente neste texto e isso é, quanto a mim, um equívoco.

Estranho é também constatar que fora de território nacional as opções sejam outras e que se dê igual realce à criatividade artística e tecnológica. Que a visão do que cabe ou não na indústria seja menos estreita e integre mais artistas que não encaixem num padrão tão óbvio. A capa do livro é uma boa metáfora desse desaparecimento da 
"arte" que se vai "esvaindo" em letras mais pequenas. A gamificação, ou seja, a aplicação de técnicas de game design em outros contextos, poderia servir como porta de entrada a uma reflexão menos rígida do território e tornaria fácil a citação de inúmeros playable media nesta história.

E não são só os jogos que desaparecem nesta narrativa possível. O blogue "Pensar Videojogos" de André Carita não é sequer citado. O número dedicado ao jogos da revista Caleidoscópio de 2003 é citado mas esquece-se a Interact, revista de arte, cultura e tecnologia, do Centro de Estudos de Comunicação e Linguagem da Faculdade de Ciências Sociais e Humanas da Universidade Nova de Lisboa, disponível on-line desde 2004, também dedicada aos jogos, que inclui textos de Gonzalo Frasca, influente crítico de jogos e designer de obras incontornáveis nos game studies; Mark Stephan Meadows, prolífico criador americano e escritor de vários livros sobre jogos e multimédia; Pedro Gadanho, comissário de Arquitectura e Design do MoMA de Nova Iorque, para citar apenas alguns autores que contribuíram para esta revista. Podemos sempre rever esta narrativa, e o autor assim o considerou na apresentação do livro, mas algumas ausências parecem demasiado flagrantes.

Outro problema parece ser o desaparecimento das mulheres nesta história possível dos videojogos em Portugal. Diz-se nas conclusões: "Actualmente, o perfil do criador português é ainda maioritariamente masculino, mas aparecem já as primeiras mulheres a trabalhar em guionismo, na arte e no design. A informática ainda domina, mas o design e as belas artes estão agora muito mais presentes [onde?], assim como se podem encontrar vários perfis ligados aos novos cursos superiores nacionais de Tecnologias da Comunicação, Audiovisuais e Multimédia. As idades são bastante mais abrangentes, situando-se entre os 20 e os 40 anos" (197).

Mulheres a trabalhar em guionismo, na arte e design, ou seja, nunca como game designers ou programadoras, criadoras independentes ou artistas... Hoje, um pouco por todo o mundo desenvolvido, as mulheres são estrategicamente "tornadas visíveis" na indústria de jogos digitais isto porque se constatou que o território está minado por uma lógica do "feito-por-homens-para-homens". Assim, um pouco por todo o lado, onde há efectiva criação lúdica, as mulheres congratulam-se por, finalmente, estarem a ganhar terreno num universo tão agreste. A visibilidade de género é fundamental para angariar novas mulheres para os universos tecnológicos e para desta forma estimular massa crítica e diminuir as desigualdades.

Finalmente, o fado dos videojogos em Portugal. Oscila-se ainda entre a megalomania explicitada por gastos insustentáveis, criações de quimeras e castelos de sonho e a "pobreza", com um pé na propaganda, dos jogos escolares e emulações sem grande criatividade. Sobressaem as imitações de outros jogos produzindo-se um 
efeito claro de desaparecimento da arte, bem evidente logo no início do livro: "os videojogos estão intimamente ligados ao aparecimento da computação mas, mais do que isso, são fruto de uma combinação de quatro ciências base: a Matemática, a Eletrónica, a Computação e a Comunicação" (1). Se a Arte não é ciência ou está no chapéu da comunicação não é claro. Parece que o autor nos quer dizer que Shigeru Miyamoto não é um artista mas antes um engenheiro. Minimizam-se aspectos artísticos e universos femininos numa estética geek que ainda sugere que neste clube "menina não entra". 